\title{
Pneumoretroperitoneum, Pneumomediastinum, Subcutaneous Emphysema After a Rectal Endoscopic Mucosal Resection
}

\author{
Hee Cheul Jung, Hyun Jin Kim, Sung Bok Ji, Jun Hyeong Cho, Ji Hye Kwak, Chang Min Lee, Wan Soo Kim, \\ Jin Ju Kim, Jae Min Lee, Sang Su Lee \\ Department of Internal Medicine, Gyeongsang National University School of Medicine, Jinju, Korea
}

An endoscopic mucosal resection (EMR) is an effective and safe therapeutic technique for treating a patient with a laterally-spreading tumor (LST). Colonoscopic-procedure-related complications are noted to be about $2.8 \%$ worldwide, and a perforation is the most common. Most colon perforations cause pneumoperitoneum. However, a perforation within the retroperitoneal portion of the colon (rectum and some of sigmoid colon) may cause an extraperitoneal perforation, and the leaking free air may induce pneumoretroperitoneum, pneumomediastinum, and subcutaneous emphysema, depending on the amount of discharged air. Herein, we present the case of a patient with an extraperitoneal colon microperforation which manifested as pneumoretroperitoneum, pneumomediastinum, and subcutaneous emphysema after an EMR for a sigmoid LST, which was successfully treated with medical treatment and endoscopic clipping.

Keywords: Colonoscopy; Perforation; Pneumoretroperitoneum; Pneumomediastinum; Subcutaneous emphysema

\section{INTRODUCTION}

As colonoscopy becomes more common, the discovery of colon polyps and colonic laterally-spreading tumors (LSTs) is rapidly increasing. With the rise in the frequency of endoscopic resections of colorectal masses detected by using endoscopy, the incidence of relevant complications is also increasing [1]. Colon perforation, as the most common complication related to colonoscopy, has been reported to occur rarely $(0.01 \%-0.2 \%)$ during diagnostic colonoscopy, but more frequently (5\%) during therapeutic colonoscopy [2].

Most colon perforations during diagnostic colonoscopy cause pneumoretroperitoneum due to air that leaks from the bowel to

Received: February 2, 2016 - Accepted: April 26, 2016

Correspondence to: Hyun Jin Kim, M.D.

Department of Internal Medicine, Gyeongsang National University School of Medicine, 15 Jinju-daero 816beon-gil, Jinju 52727, Korea

Tel: +82-55-755-8721, Fax: +82-55-755-9078,

E-mail: hee-cheul@hanmail.net

(C) 2016 The Korean Society of Coloproctology

This is an open-access article distributed under the terms of the Creative Commons Attribution NonCommercial License (http://creativecommons.org/licenses/by-nc/4.0) which permits unrestricted non-

commercial use, distribution, and reproduction in any medium, provided the original work is properly cited. the peritoneal cavity. The incidence of pneumoretroperitoneum is extremely rare for retroperitoneal perforations that occur in the rectum or a part of the sigmoid colon; however, air may leak from the bowel into the retroperitoneal space [3]. In such a case, pneumoretroperitoneum, pneumomediastinum, and subcutaneous emphysema may develop, depending on the amount of leaking air. The authors experienced the case of a patient in whom pneumoretroperitoneum, pneumomediastinum, and subcutaneous emphysema occurred after a rectal endoscopic mucosal resection (EMR) for the treatment of a LST located in the sigmoid colon; the patient improved with conservative treatment. Accordingly, we attempt to report the results of that case, as well as the results of a review of the literature related to that case.

\section{CASE REPORT}

A woman aged 58 years visited Gyeongsang National University Hospital to have a flat-elevated LST (tubular adenoma and topical high-grade dysplasia) with a size of $10 \mathrm{~mm}$, which was discovered in the sigmoid colon by using colonoscopy, removed. At her visit, vital signs were as follows: blood pressure $110 / 80 \mathrm{mmHg}$, pulse rate 24 heats/min and body temperature $36^{\circ} \mathrm{C}$. No abnormal findings were noted in the physical examination. In the laboratory findings, 
Volume 32, Number 6, 2016

the results of the blood tests were white blood cell (WBC) 4,260/ $\mathrm{mm}^{3}$, hemoglobin (Hb) $11.7 \mathrm{~g} / \mathrm{dL}$, platelets (PLT) $214,000 / \mathrm{mm}^{3}$, blood urea nitrogen $13.8 \mathrm{mg} / \mathrm{dL}$, creatinine $0.64 \mathrm{mg} / \mathrm{dL}$, sodium $137.8 \mathrm{mmol} / \mathrm{L}$, potassium $3.6 \mathrm{mmol} / \mathrm{L}$, aspartate aminotransferase $21 \mathrm{U} / \mathrm{L}$, alanine aminotransferase $20 \mathrm{U} / \mathrm{L}$, total bilirubin $0.89 \mathrm{mg} / \mathrm{dL}$, and albumin $4.0 \mathrm{~g} / \mathrm{dL}$.

An EMR was performed after polyethylene glycol bowel preparation. Endoscopic hemostasis or endoscopic clipping using hot biopsy forceps was conducted for the fundus of the lesion. No obvious perforations were seen during the procedure (Fig. 1). No symptoms related to perforations, such as abdominal distension, chest pain and dyspnea, were identified in the physical examina- tion immediately after the procedure. However, we observed the condition over time due to the finding of mild, lower-abdomen tenderness. The patient complained of neck pain 3 hours after the procedure. Crepitus in the right neck and upper chest, which had not been identified in the physical examination right after the procedure, was palpated. In the chest X-ray, subcutaneous emphysema in the right neck and free air in the mediastinum were observed. Free air in the retroperitoneum was seen in the abdominal X-ray (Fig. 2A). As a result, we rendered a diagnosis of pneumoretroperitoneum and subcutaneous emphysema related to the procedure.

We decided to treat the patient conservatively because her vital
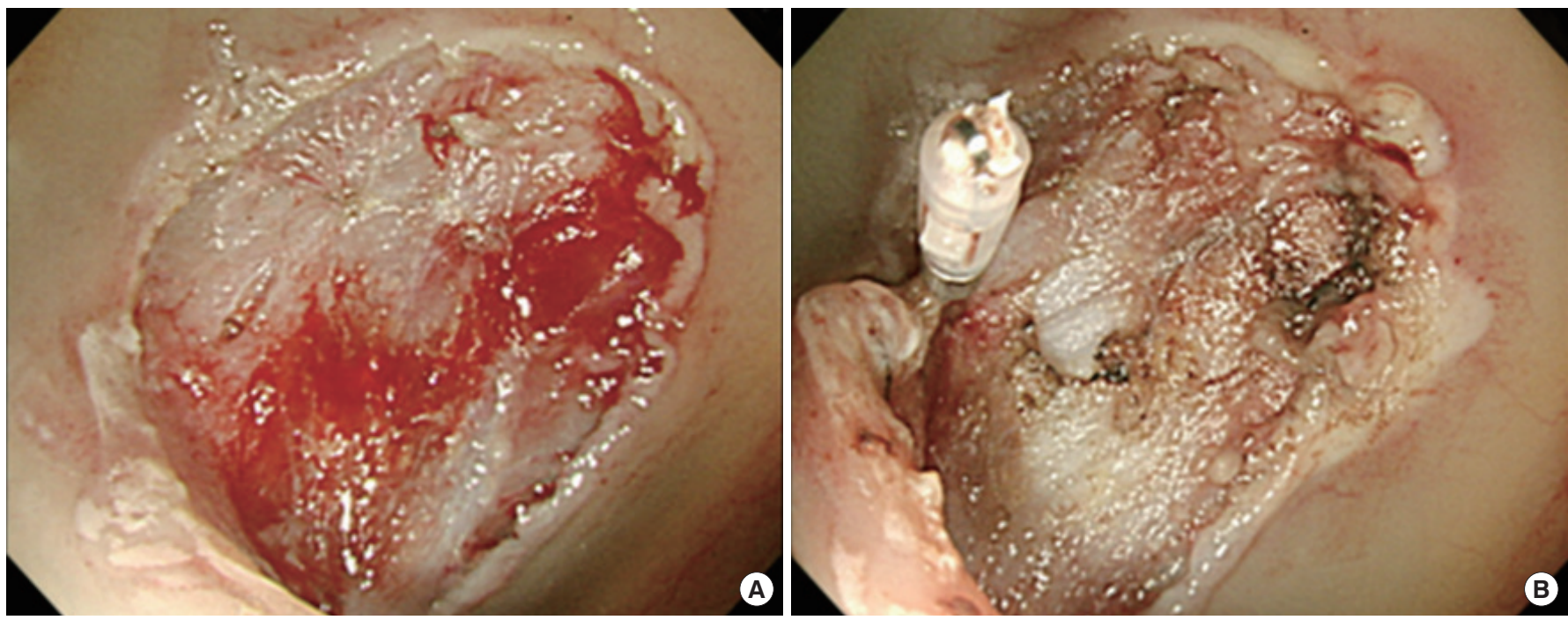

Fig. 1. Colonoscopic finding. (A) Endoscopic mucosal resection site of the sigmoid colon. No definite perforation is seen. (B) Prophylactic clipping and hot biopsy coagulation were done.
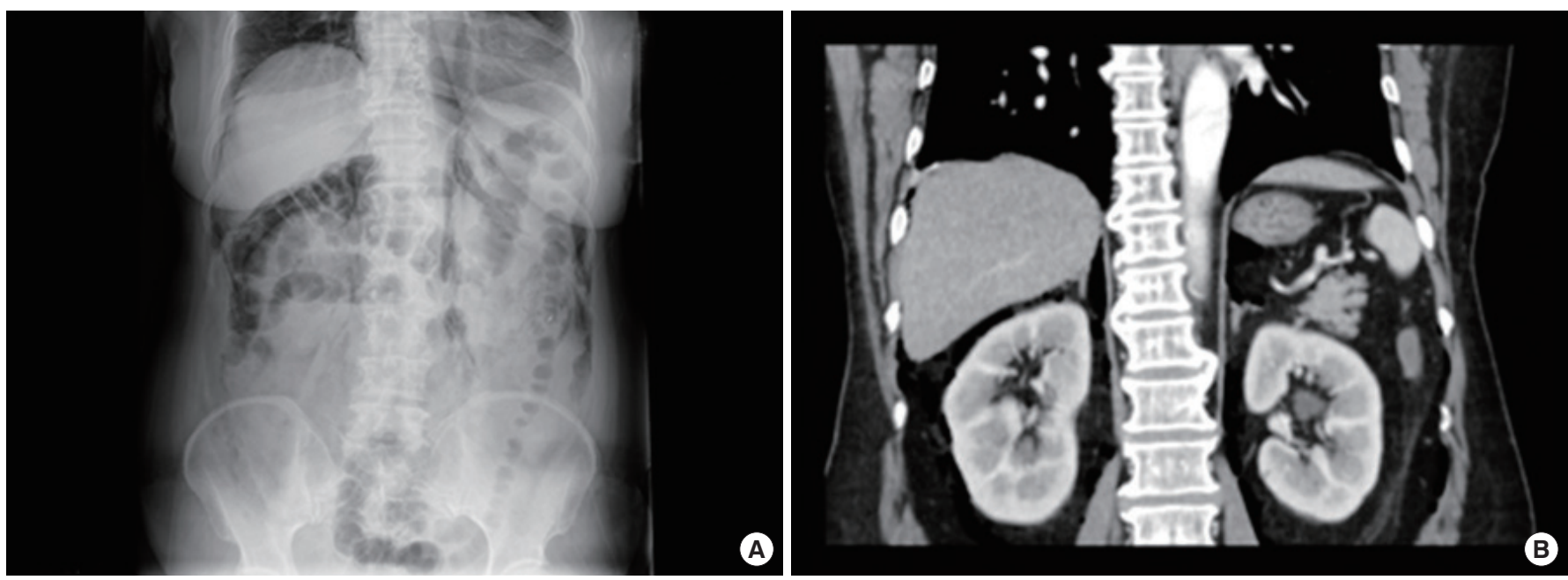

Fig. 2. Abdomen X-ray and abdominal computed tomography (CT) findings. (A) Diffuse bilateral retroperitoneal air is seen on an X-ray of the abdomen. (B) Retroperitoneal air at the perinephric area was seen on abdominal CT. No subdiaphragmatic air was seen. 


\section{Coloproctologagy}
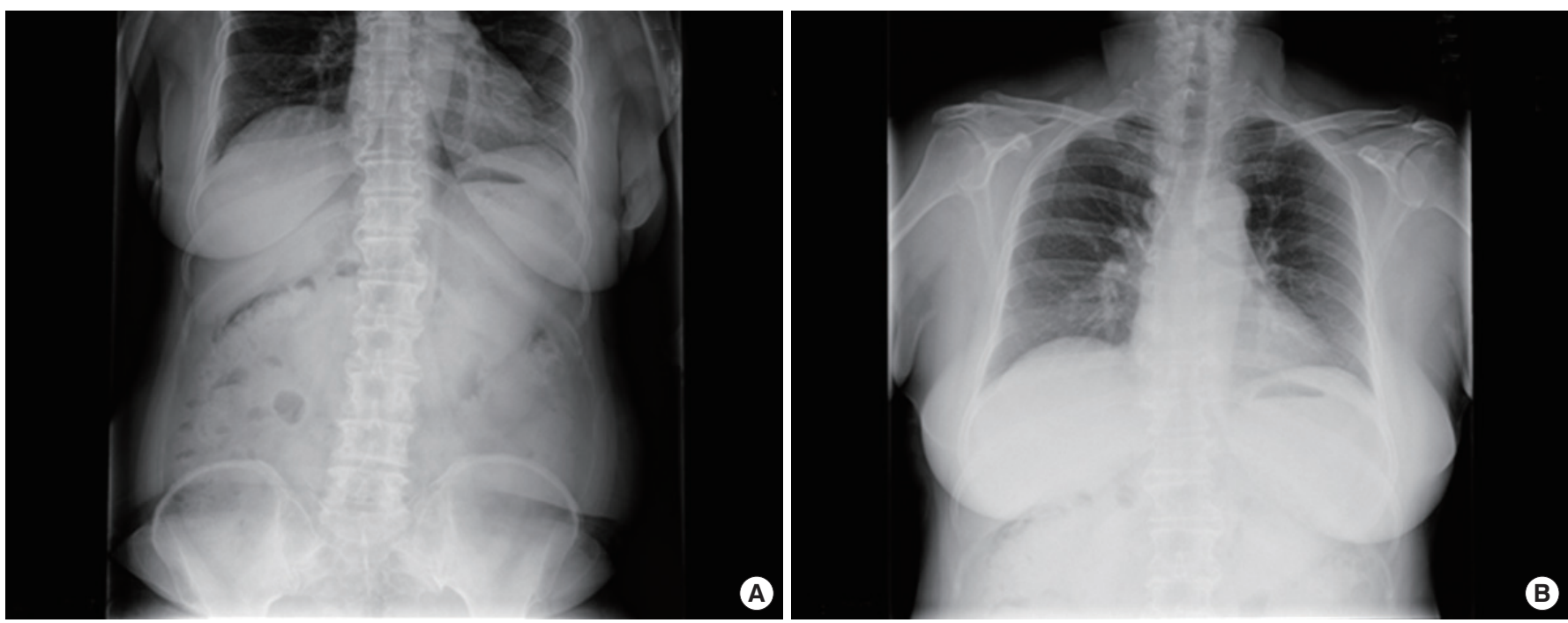

Fig. 3. Follow-up chest and abdominal X-ray findings. (A, B) Pneumoretroperitoneum and pneumomediastinum were improved after medical treatment.

signs had not changed and leukocytosis was not indicated. Intravenous feeding and antibiotics (ceftriaxone, metronidazole) were prescribed immediately. With the use of a nasal cannula, oxygen was delivered at a rate of $2 \mathrm{~L} / \mathrm{hr}$ in order to rapidly absorb subcutaneous emphysema. Vital signs on the day after the procedure included a blood pressure of $130 / 90 \mathrm{mmHg}$, a pulse rate of 80 beats/min, a respiratory rate of $18 \mathrm{breath} / \mathrm{min}$, and a body temperature of $36.3^{\circ} \mathrm{C}$. The results on physical examination showed that the patient still had not only subcutaneous emphysema in the right neck and under the collarbone but also tenderness of the left, lower abdomen. The abdominal X-ray showed that free air in the retroperitoneum had declined. The results of blood test were

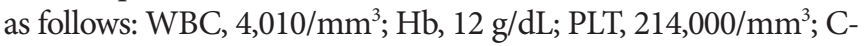
reactive protein $(\mathrm{CRP}), 27.2 \mathrm{mg} / \mathrm{L}$, and erythrocyte sedimentation rate, $24 \mathrm{~mm} / \mathrm{hr}$. On the same day, free gas leaking from the retroperitoneum to the mediastinum was observed on abdominal computed tomography. However, no questionable findings, such as an obvious intestinal perforation, peritoneal fluid, or peritonitis, were noted (Fig. 2B).

Diet was started from water intake at the 4th day after the procedure, and an oral antibiotic (ciprofloxacin) was administered instead of injectable antibiotics. At the 5th day after the procedure, the abdominal pain was reduced markedly, and symptoms, including diarrhea and fever after the start of dietary regimen, were not reported. After that, the patient showed no findings such as fever. The patient was discharged from the hospital on the 6th day after the procedure owing to her general symptoms having been alleviated, and she was instructed to continue oral administration of antibiotics. We observed the condition of the patient in the outpatient clinic one week after her leaving the hospital, and the patient did not complain of abdominal pain. The blood-test results

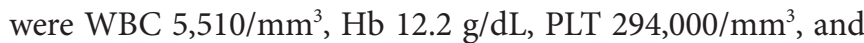
CRP $0.8 \mathrm{mg} / \mathrm{L}$. The abdominal X-ray showed only a small amount of free gas (Fig. 3).

\section{DISCUSSION}

LSTs in the colon are epithelial neoplasms that have a low vertical axis and extend widely along the colonic mucosa. An EMR is known as an effective treatment for patients with LSTs [4]. According to reports, perforations caused by rectal EMRs are rare; in addition, the frequency of perforations caused by rectal EMRs $(0.091 \%)$ is higher than the frequency caused by polypectomy $(0.017 \%)$, but is lower than the frequency caused by endoscopic submucosal dissections (3.3\%) [5]. Most perforations cause by colonoscopy are intraperitoneal perforations. In these cases, air caused by the desquamation of the colon wall shifts to the retroperitoneal space along the mesentery: perforations are located in the retroperitoneum, such as the rectum or the sigmoid colon; the perforations are small; the amount of air that leak from the bowel is small. This results in pneumoretroperitoneum, pneumomediastinum, and subcutaneous emphysema [2]. In some cases, when a large amount of free air exists in pneumoretroperitoneum, free air shifts to the mediastinum beyond the facial plane, and a pneumothorax occurs by the rupture of mediastinal pleura [2]. Abdominal pain, the most common symptom of colonic perforations, appears during or after the procedure, depending on the amount of leaked air. Pain is occasionally seen 72 hours after the procedure [6]. Furthermore, such symptoms as fever, bleeding, physconia and peritonitis can be seen, but these symptoms appear differently, depending on the position and the size of the perforation, the degree of bowel preparation, and the underlying disease. 
Table 1. Clinical characteristics of patients with a retroperitoneal perforation

\begin{tabular}{lcclccc}
\hline Author & $\begin{array}{c}\text { Age } \\
(\mathrm{yr})\end{array}$ & Sex & Location & $\begin{array}{c}\text { Size } \\
(\mathrm{mm})\end{array}$ & $\begin{array}{c}\text { Diet day } \\
(\text { day })\end{array}$ & $\begin{array}{c}\text { Hospital day } \\
(\text { day })\end{array}$ \\
\hline Park et al. [9] & 46 & Female & Sigmoid & 20 & 3 & 10 \\
Yim et al. [10] & 73 & Female & Rectum & NA & 9 & NA \\
Kim et al. [11] & 47 & Female & Sigmoid & 8 & 5 & 14 \\
Shin et al. [12] & 70 & Female & Rectum & 2 & 5 & 11 \\
Murariu et al. [13] & 50 & Female & Sigmoid & NA & 5 & 7 \\
\hline
\end{tabular}

NA, not applicable.

On the other hand, about $10 \%$ of the patients remain symptomfree. If a perforation is suspected, the presence of an intraperitoneal perforation should be identified by observing the shadow of free air in the subphrenic space by means of an abdominal plain film assessment in an early stage. If the diagnosis is unclear, abdominal CT can be helpful [6].

In the past, surgery played an important role in the treatment of patients with perforations related to colonoscopy. However, recently, conservative treatment with endoscopic clipping has been reported to be an effective treatment, during or right after the procedure, for perforations [7]. Conservative treatment can be preferentially considered under these conditions: the patient is in a clinically-stable state; the symptom of peritonitis is not severe; the degree of bowel preparation is good; the perforation is detected early after its occurrence; the patient has no retroperitoneal perforations and no underlying diseases requiring surgery [8]. Successful treatment of patients with retroperitoneal perforations by using endoscopic clipping has been reported in patients with a good-quality bowel preparation and stable vital signs [9]. Especially, a perforation that occurs during the procedure is less likely to cause peritonitis or septicemia due to fecal leakage to the perforation area because the degree of bowel preparation is relatively good. For this reason, endoscopic clipping and conservative treatment are preferable to surgery. According to studies on conservative treatment for patients with perforations that occurred during diagnostic or therapeutic colonoscopy (Table 1) [9-13], women were more common in the reported cases. However, in international reports, no statistically significant differences between men and women were found $[14,15]$. Oral diet in patients was started at a median of 5 days after the procedure (3-9 days), and the lengths of hospital stay were 7-14 days. The position of the perforation was in the rectum or the sigmoid colon. This is considered to be related to the anatomic features of the sigmoid colon, which has a severe curvature and better elasticity compared to other large intestines.

Reports in the literature that analyzed the cases of other patients with perforations that occurred after colonoscopy showed that the frequency of perforations in the rectum or the sigmoid colon was higher than it was in other parts of the large intestine, but no significant differences in the clinical signs of the patients and the treatment modalities based on the positions of the perforations were noted. The selection of conservative or surgical treatment was determined based on the position of the perforation, the degree of bowel preparation and the clinical symptoms of the patients.

For the case of this study, conservative treatment was determined by factors including complete removal of the lesion, preventive clipping, stable vital signs, laboratory findings, good-quality bowel preparation, the presence of a retroperitoneal perforation, and the presence of microperforations. Another study reported that conservative treatment with endoscopic band ligation was successful, although intraperitoneal free air from the perforations was present after the colonoscopy. That study had differences in some aspects in comparison with the case of this study: In that study, endoscopic clipping was difficult to perform because the forward end section of the endoscope was parallel to the position of the perforated area, so an endoscopic band ligation was performed; intraperitoneal free air was identified. In our study, the patient underwent preventive clipping at the end of the procedure. In that study, a conservative treatment was decided upon after carefully considering the factors of the good-quality bowel preparation, stable general symptoms and state of consciousness.

Pneumoretroperitoneum, pneumomediastinum, and subcutaneous emphysema are known to be complications that occur, although extremely rarely, after an EMR for the treatment of patients with LSTs. In our case, these complications were seen after the EMR, but were completely cured with conservative treatment. Notwithstanding the lack of a shadow of free air in the subphrenic space after the procedure, if abdominal pain continues, a retroperitoneal perforation should be suspected.

\section{CONFLICT OF INTEREST}

No potential conflict of interest relevant to this article was reported.

\section{REFERENCES}

1. Repici A, Pellicano R, Strangio G, Danese S, Fagoonee S, Malesci A. Endoscopic mucosal resection for early colorectal neoplasia: pathologic basis, procedures, and outcomes. Dis Colon Rectum 2009;52:1502-15.

2. Lohsiriwat V. Colonoscopic perforation: incidence, risk factors, management and outcome. World J Gastroenterol 2010;16:425-30.

3. Marwan K, Farmer KC, Varley C, Chapple KS. Pneumothorax, pneumomediastinum, pneumoperitoneum, pneumoretroperitoneum and subcutaneous emphysema following diagnostic colonoscopy. Ann R Coll Surg Engl 2007;89:W20-1.

4. Tanaka S, Haruma K, Oka S, Takahashi R, Kunihiro M, Kitadai Y, et al. Clinicopathologic features and endoscopic treatment of superficially spreading colorectal neoplasms larger than $20 \mathrm{~mm}$. 
Gastrointest Endosc 2001;54:62-6.

5. Oka S, Tanaka S, Kanao H, Ishikawa H, Watanabe T, Igarashi M, et al. Current status in the occurrence of postoperative bleeding, perforation and residual/local recurrence during colonoscopic treatment in Japan. Dig Endosc 2010;22:376-80.

6. Gedebou TM, Wong RA, Rappaport WD, Jaffe P, Kahsai D, Hunter GC. Clinical presentation and management of iatrogenic colon perforations. Am J Surg 1996;172:454-7.

7. Cho YK, Nam SW, Kim HC, Ko EY, Kim YH, Park SM, et al. Conservative treatment of colonoscopic perforations. Korean J Gastrointest Endosc 2006;33:20-25.

8. Kang HY, Kang HW, Kim SG, Kim JS, Park KJ, Jung HC, et al. Incidence and management of colonoscopic perforations in Korea. Digestion 2008;78:218-23.

9. Park NS, Choi JH, Lee DH, Kim YJ, Kim ES, Jung SW, et al. Pneumoretroperitoneum, pneumomediastinum, peumopericardium, and subcutaneous emphysema after colonoscopic examination. Gut Liver 2007;1:79-81.

10. Yim JK, Kim YM, Park SN. Pneumothorax, pneumomediastinum, subcutaneous emphysema, pneumoretroperitoneum sec- ondary to colonoscopic perforation. Korean J Gastrointest Endosc 2011;42:38-42.

11. Kim SA, Kim JH, Lee JH, Yang CH. A case of successful clipping of a colonic perforation during diagnostic colonoscopy. Korean J Gastrointest Endosc 2009;38:348-51.

12. Shin CJ, You KW, Pyo SB, Moon HC, Hong GY, Oh DH, et al. A case of pneumoperitoneum, pneumoretroperitoneum, pneumomediastinum, and subcutaneous emphysema after endoscopic submucosal resection. Korean J Gastrointest Endosc 2007;35:11620.

13. Murariu D, Tatsuno BK, Tom MK, You JS, Maldini G. Subcutaneous emphysema, pneumopericardium, pneumomediastinum and pneumoretroperitoneum secondary to sigmoid perforation: a case report. Hawaii J Med Public Health 2012;71:74-7.

14. Namgung H, Cho MK, Lee KH, Myung SJ, Yang SK, Yu CS, et al. Management of colonic perforation during colonoscopic procedure. Korean J Gastrointest Endosc 2005;30:188-93.

15. Anderson ML, Pasha TM, Leighton JA. Endoscopic perforation of the colon: lessons from a 10-year study. Am J Gastroenterol 2000; 95:3418-22. 